\title{
The Experience and Inspiration of the Construction of San Francisco Bay Area
}

\author{
Jiali $\mathrm{Zhu}^{1, *}$ \\ ${ }^{1}$ Jiangxi Institute of Economic Administrator, Nanchang, Jiangxi \\ *Corresponding author. Email:942177188@qq.com
}

\begin{abstract}
The Bay Area is a coastal region with location and cluster advantages. From a global perspective, the Bay Area economy formed on this basis leads the development of global economy and science and technology. This paper takes the San Francisco Bay Area as an example to understand the general situation of the Bay Area and its development process, and to deeply discuss and analyze the successful experience of the construction of the Bay Area, so as to provide reference for the construction of the Bay Area in China.
\end{abstract}

Keywords: Bay Area economy, Science and technology innovation, Collaborative development.

\section{BASIC OVERVIEW OF THE SAN FRANCISCO BAY AREA}

The San Francisco bay area, one of the world's four big bay, in the fourth metropolitan areas in the United States, is located in northern California in the United States, vast gulf, water land transport facilities, the total population of more than 7.7 million people, is composed of nine counties, according to the geographical location is the bay can be divided into north bay, south bay, east bay, the city of San Francisco and peninsula. Among them, North Bay is rich in resources, South Bay is the gathering place of high-tech, information and electronic industries, East Bay has the largest port in the Bay Area and excellent education resources, San Francisco is the central city of San Francisco Bay Area and the main population gathering area, and Peninsula is the connection between San Francisco City and South Bay.

\section{THE DEVELOPMENT OF THE SAN FRANCISCO BAY AREA}

From the 1840 s to the present day, the development of the San Francisco Bay Area can be divided into five stages: the embryonic stage, the preliminary stage, the accelerated stage, the stable stage and the mature stage now. Among them, in the initial development stage, the Bay Area's development mainly relies on the driving force of the government, while in the mature development stage, the Bay Area's development is mainly market-oriented, relying on the ability of scientific and technological innovation, and has become the backbone to promote the global high-tech industry reform. San Francisco Bay Area has strong basic scientific research strength, also known as the "scientific research bay area". Its central city San Francisco is listed in the 2019 Global Major Cities Basic Frontier Research Monitoring Index Top 20 Cities. Silicon Valley, the southern science and technology research base, leads the world in science and technology strength.

In the future, the Bay Area will continue to give full play to its internal resource advantages, promote the in-depth integration of basic science and high-tech industries, and form a more internationally competitive industrial cluster economy.

\section{SUCCESSFUL EXPERIENCE IN THE CONSTRUCTION OF THE SAN FRANCISCO BAY AREA}

San Francisco Bay Area is a world-famous bay area dominated by science and technology innovation economy. Its successful experience in economic development is worth learning from. The San Francisco Bay Area is now in a mature development stage, and its infrastructure construction is relatively complete. Therefore, it is mainly affected by endogenous and exogenous factors. Endogenous driving force is an internal force formed in the development process of the Bay Area's economic form[1], which can be mainly manifested as the core driving force dominated by innovation. From the perspective of regional economics, 
the Bay Area economy is a region with strong self-organizing ability. The self-organizing ability of the Bay Area economy development is composed of relatively perfect market system, various professional markets, financial markets and service industries. Exogenous motivation is briefly described as the support and guidance of external forces, such as external competition and government planning. In this paper, the success of the construction of the San Francisco Bay Area can be summarized as endogenous driving force mainly based on technological innovation and regional collaboration, and exogenous driving force mainly based on government support and guidance.

\subsection{Strong Scientific and Technological Innovation Capability}

Among the four Bay Areas, the San Francisco Bay Area has the highest quality labor force[2], and formed a complete innovation ecosystem of university, enterprise, venture capital and government[3]. The Bay Area is home to five world-class research universities: Stanford University, University of California at Berkeley, University of California at Davis, University of California at San Francisco, and University of California at Santa Cruz; And five national research laboratories: Lawrence Berkeley National Laboratory, Lawrence Livermore National Laboratory, NASA Ames Research Center, USDA Western Regional Research Center, and the Stanford Linear Accelerator Center[4].The unique cultural atmosphere of the San Francisco Bay Area, the continuous export of high-quality talents and the continuous transformation of the research and development achievements of universities provide a solid force for the improvement of the Bay Area's scientific and technological innovation ability. In addition, the perfect modern property rights protection system makes the talents engaged in scientific and technological innovation work more enthusiastic.

\subsection{The Role of Coordinated Development among Regions}

Regional collaborative development is a multi-dimensional and multi-level comprehensive concept, and the essence of regional collaborative development is the common enhancement of regional interests [5].The regional coordinated development of San Francisco Bay Area first benefits from the city planning in the early stage of the San Francisco Bay Area, and the function division among the major cities is relatively clear. Therefore, there is no competitive relationship between different cities. The financial service industry of San Francisco, the technological innovation industry of San Jose, and the port industry and commerce of Oakland drive each other and promote the overall cooperative development of the Bay Area with diversified industrial types and reasonable regional industrial structure [6].Within the Bay Area, factors of production flow, and enterprises on the industrial chain give play to their own resource advantages. In various stages of enterprise scientific and technological research and development, achievement transformation, industrialization development and so on, all kinds of social resources can be fully mobilized and allocated to meet the resource needs of scientific and technological enterprises [1].

\subsection{Effective Guidance of Government Policies}

The steady development of market economy needs the power of government macro-control and provides strong support. For the Bay Area, the government provided strong support in the early stages of its development. Among them, the federal government began to regulate the San Francisco Bay Area in the 1990s, which greatly stimulated the vitality of the technology market in the Silicon Valley area [7].With the continuous prosperity of the Bay Area economy, the San Francisco Bay Area has also constructed a set of complete and efficient marketization mechanism from technology to market, among which the "entrepreneur in residency" program, in which the government directly purchases scientific research achievements, is particularly noteworthy.

\section{ENLIGHTENMENT FROM THE CONSTRUCTION OF THE SAN FRANCISCO BAY AREA}

Guangdong-Hong Kong-Macao Greater Bay Area was officially launched in the Government Work Report of the Fifth Session of the Twelfth National People's Congress in 2017. It has great development potential, but it has not been established for a long time. The gathering effect of high-level talents is not strong, and all kinds of policies are still under continuous improvement. Therefore, drawing lessons from the effective practices of the San Francisco Bay Area, the construction roads of China's Bay Area, including the Guangdong-Hong Kong-Macao Greater Bay Area, can be planned and improved from the following three aspects.

\subsection{Improve the Innovation Ecosystem}

The improvement of the innovation ecology in the Bay Area can be carried out in the following aspects: first, optimizing and enriching the internal scientific and educational resources, improving the conversion rate of the research and development results of universities in the region, so that the output of talents from colleges and universities can match the demand of industrial talents; Second, to build a high-end talent structure to boost industrial upgrading; Third, strengthen the protection of property rights, stimulate the innovation 
power of scientific and technological talents; Fourth, continuously innovate financial services, broaden the source of capital channels; Fifth, foster an open and inclusive cultural atmosphere and encourage innovation.

\subsection{Coordinated Economic Development}

The promotion of regional coordinated development can be carried out through the following aspects: First, to achieve the effective coordination of resources among universities, markets and enterprises, and improve the efficiency of resource allocation; Second, continuously improve the transportation layout and urban layout, reduce the logistics and transportation costs inside and outside the region, give full play to the advantages of the cities in the Bay Area, and build a multi-level system of industrial clusters, ports and urban clusters with division of labor; Third, optimize the flow of factors within the region to promote the interconnection and positive interaction among cities in the Bay Area; Fourth, continuously deepen the supply-side structural reform in the Bay Area to promote industrial upgrading and sustainable economic development.

\subsection{Adhering to Government Macro-control}

Firstly, optimize tax policies to attract a large number of high-quality enterprises; Secondly, standardize venture capital investment to benefit small and micro businesses. Thirdly, the government funds support, increase the regional infrastructure construction, capital flows into the enterprise's basic innovation research in order to ease the pressure of enterprise R\&D investment; Fourthly, the rational distribution of colleges and universities and the layout of disciplines should be planned, so as to form the aggregation effect of high-end talents, unblock the channels for the transformation of scientific and technological innovation achievements, and make the development of disciplines and industries complement each other.

\section{CONCLUSION}

Throughout the bay area all over the word, the development of the bay area economy has significant geographical advantage and the cluster effect, the breakthrough of the development of the administrative boundaries, realize the regional coordinated, create a good atmosphere of economic development, combined with science and education, venture capital, culture, enterprise, talents, information, and other important resources, leading the regional and even global system, economy, science and technology, the development direction of education, etc. The experience and inspiration of the construction of San Francisco Bay Area will contribute to the development of the Guangdong-Hong Kong-Macao Greater Bay Area.

\section{REFERENCES}

[1] Wu Fenglan, Tao Yitao, Shen Yong. Research on the dynamic mechanism of economic evolution in the Bay Area: An international case and its enlightenment $[\mathrm{J}]$. Science and Technology Progress and Countermeasures, 2015, 32(23):31-35.

[2] Lu Zhiguo, Pan Feng, Yan Zhenkun. Research on economic comparison and comprehensive evaluation of global bay area $[\mathrm{J}]$. Science and Technology Progress and Countermeasures, 2015, 32(11):112-116.

[3] Ding Xuguang. Building the Guangdong-Hong Kong-Macao Greater Bay Area Innovation Community by Drawing on the Innovation Experience of San Francisco Bay Area [J].To explore, 2017, (6): 27 to $30+59$.

[4] Fan Mingjie. Development Enlightenment of San Francisco Bay Area [J]. Urban and Rural Construction, 2019, (04):74-76.

[5] Zhang Manyin, Quan Rong. Evaluation of Beijing-Tianjin-Hebei regional collaborative development [J]. Statistics and Decision, 2020, 36(04):72-76.

[6] Fan Mingjie. Regional synergy mechanism of the world bay area $[\mathrm{J}]$. Urban and Rural Development, 2019, (20):67-69.

[7] Li Nan, Wang Zhouyi, Yang Yang. A Comparative Study on the Development Patterns of the Global Four Bay Areas under the Background of Innovation-driven Development Strategy [J].Think Tank Theory \& Practice,2019,4(03):80-93. 